\title{
A clinical and genetic study of Hunter's syndrome. 2 Differences between the mild and severe forms
}

\author{
I D YOUNG, P S HARPER, R G NEWCOMBE, AND I M ARCHER
}

From the Departments of Medical Genetics and Medical Statistics, University Hospital of Wales and the Welsh National School of Medicine, Cardiff.

SUMMARY Comparison of the disease course in patients with the severe and mild forms of Hunter's syndrome indicates that the severely affected boys show a higher incidence of behavioural disorder, diarrhoea, convulsions, and terminal cachexia. It is proposed that all of these differences may be attributed to the underlying neurodegeneration which characterises the severe form of the disease. A means of predicting the ultimate disease outcome in a young isolated case is presented.

In the accompanying paper it has been established that patients with Hunter's syndrome tend to fall clearly into one of two groups depending upon the presence or absence of intellectual deterioration. This report examines those clinical features which distinguish each form of the disease. In addition a method is presented for predicting the ultimate disease course in a young isolated case.

\section{Patients and methods}

Of the 47 living patients ascertained, 31 were personally examined either in the family home or at a local hospital. The hospital records of the remaining 16 boys were available for review. Details of the 41 dead patients were obtained from hospital records or discussion with living relatives or both.

The following observations are based upon analysis of the disease course in 52 severely and 31 mildly affected patients. Cases 17 to 22 and 75 , who were discussed in the previous paper, have been included with the mildly affected cases because there was no firm evidence of neurodegeneration in these patients.

\section{Results}

\section{NATURAL HISTORY}

The ages of onset and death in the study patients are shown in histogram form in figs 1 and 2 . In fig 1 age of onset relates to that age at which either a parent or professional health care attendant became seriously concerned about the child's welfare. When foreknowledge of the family history had diverted

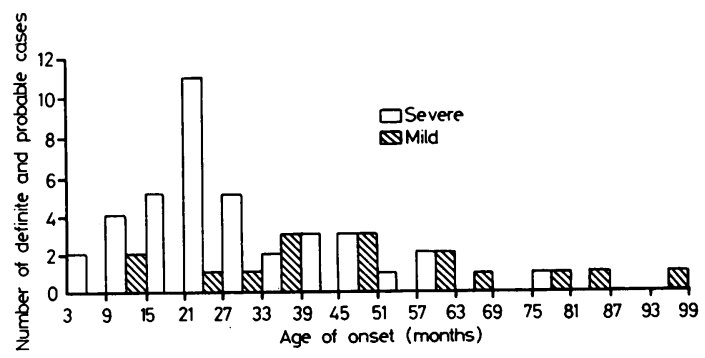

FIG 1 Age of onset in months.

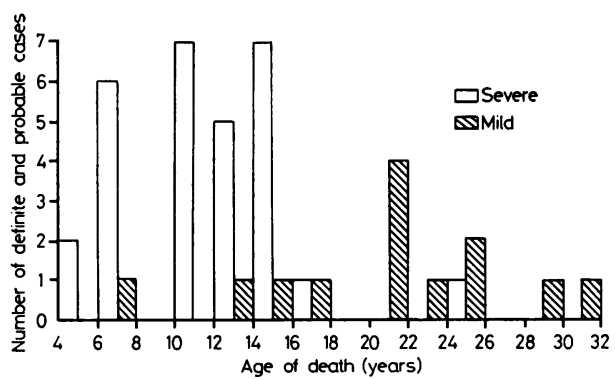

FIG 2 Age of death in years.

TABLE 1 Natural history parameters in mild and severe Hunter's syndrome.

\begin{tabular}{|c|c|c|c|c|}
\hline & \multicolumn{2}{|l|}{ Mild } & \multicolumn{2}{|l|}{ Severe } \\
\hline & Mean & $S D$ & Mean & $S D$ \\
\hline $\begin{array}{l}\text { Age of onset } \\
\quad(n=55)\end{array}$ & $4 \cdot 30$ & $\begin{array}{r}2.04 \\
p<0.02\end{array}$ & $2 \cdot 47$ & $1 \cdot 31$ \\
\hline $\begin{array}{l}\text { Age of death } \\
\quad(n=42)\end{array}$ & $21 \cdot 70$ & $\begin{array}{c}7.84 \\
\mathrm{p}<0.001\end{array}$ & $11 \cdot 77$ & $4 \cdot 20$ \\
\hline $\begin{array}{l}\text { Interval onset to death } \\
\quad(n=28)\end{array}$ & $18 \cdot 06$ & $p<0.001$ & 9.92 & $3 \cdot 69$ \\
\hline
\end{tabular}

All values are in years.

Statistical significance assessed by log rank test. 


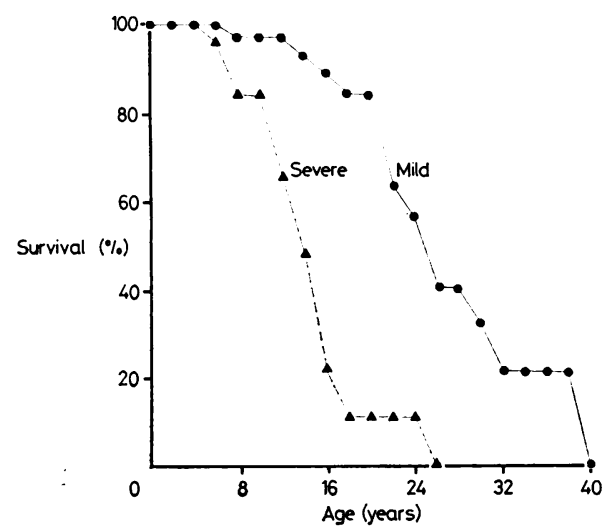

FIG 3 Pattern of survival in the severe and mild forms.

attention to the child at an earlier age than would otherwise have occurred, these data were not included. Table 1 summarises the mean values for these parameters along with the interval from onset to death. Fig 3 shows life table plots for survival by age for both forms of the disease.

\section{PRESENTING SIGN OR SYMPTOM}

In the mildly affected cases serious illness was usually first suspected by a paediatrician seeing the child for a relatively trivial reason. Thus, facial appearance was the commonest presenting feature. The commonest factor initiating concern leading to the diagnosis in the severely affected boys was developmental delay. In over half the cases the parents themselves realised that something was wrong.

\section{CAUSE OF DEATH}

Among the mildly affected cases death resulted primarily from cardiac problems in seven patients, bronchopneumonia in two, and a combination of cardiac and respiratory problems in one. Three patients died while awaiting, undergoing, or recovering from surgery: in these patients upper respiratory airway obstruction played a crucial role.

In the severely affected group, the death certificate frequently described the cause of death as pneumonia, but inspection of hospital records revealed that many of these boys had been in a grossly emaciated state before death so that cachexia was the underlying cause of death, with pneumonia simply providing the coup de grâce. Of the 25 patients for whom information concerning the terminal illness was available, 15 had been in a bed-ridden cachexic state before death. Respiratory infection accounted for the death of a further seven, of whom two died of pneumonia during outbreaks of influenza. The remaining three boys died of postoperative complications, acute cardiac failure with pneumonia, and acute upper airway obstruction.

PHYSICAL APPEARANCE AND GROWTH MEASUREMENTS

In their physical appearance both groups of patients showed a similar phenotype with only the dull apathetic facies of the older severely affected boys distinguishing the two. Patients in both groups tended to be short with all the study patients aged 10 years or over lying below the 3rd centile. Both groups of patients showed initial abnormally rapid head growth which persisted in the mild group but ceased after 7 years in some of the severely affected boys.

\section{PSYCHOSOCIAL PROBLEMS}

The early years of life in the severely affected boys were characterised by severe behavioural disturbance including overactivity $(76 \%)$, obstinacy $(47 \%)$, aggression $(42 \%)$, and exuberance $(26 \%)$. Figures in brackets indicate the incidence of these problems in the 38 patients for whom reliable information could be obtained. In contrast no abnormal behaviour was reported in the majority of the mildly affected boys. However, this latter group tended to show evidence of psychological disturbance during and after adolescence as they struggled to come to terms with their unusual appearance and poor prospects. These various problems have been described in full elsewhere. ${ }^{1}$

\section{SYSTEMS}

Both groups showed a high incidence of cardiac and respiratory disease. Cardiac symptoms, primarily valvular in origin, were noted in $75 \%$ of the mildly affected cases aged over 15 years. Among younger cases in both groups cardiac involvement was usually asymptomatic, being overshadowed in the severely affected boys by neurological involvement. Upper and lower respiratory tract disease occurred frequently in both groups of patients. The occurrence of tracheal stenosis and the dangers of general anaesthesia in one family have already been documented. ${ }^{2}$

Similarly, both groups showed a high incidence of hepatosplenomegaly and inguinal and umbilical herniae. However, diarrhoea was noted in 22 out of $34(65 \%)$ of the severely affected boys as opposed to three out of $16(19 \%)$ of the mild cases. This diarrhoea was chronic and intractable, thereby generating enormous problems for the patients' hapless parents.

Progressive neurological involvement dominated the disease course of the severely affected cases. By the age of 6 years developmental skills began to plateau, thereafter regressing, so that by 10 years 
TABLE 2 Differences between mild and severe Hunter's syndrome.

\begin{tabular}{|c|c|c|}
\hline & Mild & Severe \\
\hline \multicolumn{3}{|l|}{ Natural history } \\
\hline Mean age of onset & $4 \cdot 3$ years & 2.47 years \\
\hline Commonest presenting feature & Facial appearance & Developmental delay \\
\hline Commonest cause of death & Cardiac disease $(62 \%)$ & Cachexia $(60 \%)$ \\
\hline Physical appearance and growth & Normal facial expression & Apathetic dull facies \\
\hline Head circumference & Very large & Large initially but reduced growth after $7 \mathrm{yr}$ \\
\hline IQ & Relatively normal & Global retardation \\
\hline Behaviour & Normal & Seriously disturbed \\
\hline \multicolumn{3}{|l|}{ Systems } \\
\hline Neurodegeneration & Incompatible with diagnosis & Diagnostic \\
\hline Convulsions & Rare $(1 / 31)(3 \%, p<0.001)$ & Common $(19 / 32)(59 \%)$ \\
\hline Diarrhoea & $\operatorname{Rare}(3 / 16)(19 \%, \mathrm{p}<0.01)$ & Common $(22 / 34)(65 \%)$ \\
\hline Carpel tunnel syndrome & Common & Rare \\
\hline
\end{tabular}

over $90 \%$ of the patients in this group were in a totally bed-ridden and helpless state. A history of ictal activity was obtained in 19 of the 32 patients aged 10 years or over. In these boys convulsions first occurred at a modal age of 12 years. Physically these patients presented a distressing spectacle with signs of emaciation and hypertonic, cold, wasted limbs.

In contrast, neurological involvement, other than unexplained papilloedema or pseudopapilloedema noted in $60 \%$ of the patients who were personally examined, was not a feature of the disease in the mild group. Only one patient had a history of convulsions. One patient aged 29 years developed an unexplained quadriparesis. Four patients had undergone surgery for correction of the carpal tunnel syndrome.

The main differences between the two forms of the disease are summarised in table 2.

\section{PREDICTION OF ULTIMATE DISEASE}

SEVERITY

Two factors emerged in this study which permit

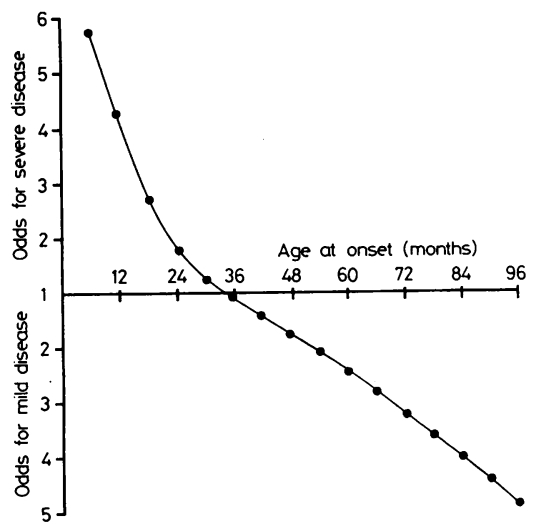

FIG 4 Odds for severe versus mild disease based on age of onset. prediction of ultimate disease severity in a young isolated case. The first is the aforementioned high incidence of behavioural disturbance found only in the severely affected patients. Thus, excessive overactivity or aggression in a young child with Hunter's syndrome would auger badly. The other means whereby disease course may be predicted can be deduced from fig 1 , which shows age of onset for those patients whose subsequent natural history was known. From these data likelihood ratios for severe or mild disease can be derived as shown in fig 4 . These odds are conditional and must be combined 8 with prior odds based on the incidence of each form of the disease when estimating the overall probable severity. In this study the incidence of the severe? form was found to be 3.38 times that of the mild. Therefore, prior odds of 3.38 to 1 may be used when computing the relative likelihood of severe or mild disease.

\section{Discussion}

It is apparent from table 2 that the mild and severe forms of Hunter's syndrome differ in several ways. Most of these differences may be attributed directly to the progressive neurodegeneration which is the hallmark of the severe form of the disease. It appears that this relentless process first manifests itself as behavioural disturbance with developmental delay in the toddler age group. Subsequent decline in intellectual faculties is accompanied by progressive wasting and spasticity with frank ictal activity appearing around the end of the first decade.

Diarrhoea in the severe form of Hunter's syndrome is a well recognised problem. In their review of 19 cases Leroy and Crocker ${ }^{3}$ described loose stools as 'characteristic'. The cause is uncertain however. In the subjects of this study no infective agents had been isolated. Several mothers noted that food seemed to 'come straight through', thereby suggesting increased gastrointestinal motility as a 
likely aetiological factor. The demonstration of membranous cytoplasmic bodies in the intestinal ganglion cells indicates that this diarrhoea may be a manifestation of autonomic neuropathy. ${ }^{4}$

The carpal tunnel syndrome has been noted in patients with mild Hunter's syndrome as early as 10 years of age. ${ }^{5}$ In this disorder the median nerve becomes constricted by thickening of the flexor retinaculum. The peripheral nerve itself is not exempt from abnormal storage, as shown by sural nerve biopsy in a 20 -year-old man with proven Hunter's syndrome, which revealed multivacuolated endoneurial fibroblasts and perineurial cells with 'zebra bodies' in the Schwann cells. ${ }^{6} \mathrm{~A}$ unique sibship has been reported consisting of three brothers aged 35,31 , and 26 years, in whom the diagnosis of Hunter's syndrome was first suspected and subsequently proven after the demonstration of similar 'zebra bodies' in epineurial fibroblasts from sural nerve biopsy. ${ }^{7}$

Other factors which suggest that the nervous system is not entirely exempt from damage in the mild form of Hunter's syndrome include papilloedema, sensorineural deafness, and discrepancy in IQ subscores, noted both in this study and in others. ${ }^{89}$ One subject in this study demonstrated a slowly progressive quadriparesis similar to the myelopathy described by Ballenger et al ${ }^{10}$ in a confirmed mild case aged 24 years. However, the extent and rate of central nervous system involvement in the severe form of the disorder permit easy separation of the mild and severe entities and the clinical correlates noted in this paper confirm their separate identity.

The data shown in fig 4 provide a means of predicting the ultimate disease severity in an isolated case based on age at onset. The provision of such information may enable both parents and health care professionals involved in the management of these children to be forewarned of, and therefore hopefully forearmed for, the many problems which lie ahead.

We are particularly indebted to the patients and their families for the co-operation received. Special thanks also go to Drs P F Benson and R Stephens for allowing us to study their patients, to Dr R Sanger for performing $\mathrm{Xg}$ blood group analyses, and to Action Research for the Crippled Child for financial support.

The following physicians kindly allowed us to visit patients under their care or provided clinical details: W A Arrowsmith, A W Blair, M Bobrow, A Bogdan, A R Boon, D P Brenton, E M CarrSaunders, C Chantler, A F Conchie, C Darby, D C Davidson, $N$ R Dennis, $R$ W Emanuel, M A Ferguson-Smith, O D Fisher, J S Fitzsimmons, D Gardner-Medwin, D Garrow, U Goecke, J Goodall, R H Gwyn-Williams, J C Hyde, J Insley, J Jancar, D M Johnston, M Joseph, B Lewis, R Lindenbaum, R Lindop, V J Marrian, J Martin, J G Masterson, R G Mitchell, J N Montgomery, J R Moore, V S Nicol, K R Norton, C H Nourse, C A Pennock, D Pickering, C T Preshaw, D A Primrose, D N Raine, D F Roberts, E G G Roberts, I S Ruthven, I B Sardharwalla, L G Scott, J M Semmens, C Shepherd, M L Shurz, B A M Smith, T E Stacey, L B Strang, M Way, C J Woods, and V L Woolley.

The observations in these papers are derived from a thesis submitted to the University of London for the degree of Doctor of Medicine by IDY, from whom full case histories may be obtained.

\section{References}

1 Young ID, Harper PS. Psychosocial problems in Hunter's syndrome. Child Care Health Dev 1981 ; $7: 201-9$.

2 Young ID, Harper PS. Long term complications in Hunter's syndrome. Clin Genet 1979;16:125-32.

3 Leroy JG, Crocker AC. Clinical definition of the HurlerHunter phenotypes. A review of 50 patients. Am J Dis Child 1966;112:518-30.

4 Elsner B. Ultrastructure of the rectal wall in Hunter's syndrome. Gastroenterology 1970;58:856-62.

5 Miner ME, Schimke RN. Carpal tunnel syndrome in pediatric mucopolysaccharidoses. Report of 4 cases. $J$ Neurosurg 1975;43:102-3.

6 Swift TR, McDonald TF. Peripheral nerve involvement in Hunter syndrome (mucopolysaccharidosis II). Arch Neurol 1976;33:845-6.

7 Karpati G, Carpenter S, Eisen AA, Wolfe LS, Feindel W. Multiple peripheral nerve entrapments. An unusual phenotypical variant of the Hunter syndrome (mucopolysaccharidosis II) in a family. Arch Neurol 1974;31 :418-22.

8 McKusick VA. The mucopolysaccharidoses. In: Heritable disorders of connective tissue. 4th ed. St Louis: Mosby, 1972.

9 Lichtenstein JR, Bilbrey GL, McKusick VA. Clinical and probable genetic heterogeneity within mucopolysaccharidosis II. Report of a family with a mild form. Johns Hopkins Med J 1972;131:425-35.

10 Ballenger CE, Swift TR, Leshner RT, El Gammal TA, McDonald TF. Myelopathy in mucopolysaccharidosis type II (Hunter syndrome). Ann Neurol 1980;7:382-5.

Requests for reprints to Dr I D Young, Department of Child Health, Leicester Royal Infirmary, PO Box 65, Leicester LE2 7LX. 